\title{
A Multifunctional Combination Incubator
}

\author{
Shaoying $\mathrm{Li}^{1,2, *}$, Zhongquan $\mathrm{Qu}^{1,2}$ and Zhiming Song ${ }^{3}$ \\ 1 School of Astronomy and Space Science, University of Chinese Academy of Sciences, Beijing 100049, China; \\ zqqu@ynao.ac.cn \\ 2 Yunnan Observatories, Chinese Academy of Sciences, Phoenix Mountain, East District, \\ Kunming 650216, China \\ 3 Institute of Intelligent Application, Yunnan University of Finance and Economics, 237 Longquan Road, \\ Kunming 650221, China; szm339255245@163.com \\ * Correspondence: lshy@ynao.ac.cn
}

Received: 31 October 2020; Accepted: 9 December 2020; Published: 15 December 2020

check for updates

\begin{abstract}
Energy, precision, and multi-functionality have become primary considerations in incubators. For example, if a part of an apparatus must be insulated, while other parts do not, then the specific part can be placed in the multi-functional incubator proposed in this paper to avoid wasting energy. The proposed incubator is composed of various parts including a platform, which is provided for debugging parts to meet the working accuracy of parts. The light windows are adjustable in height to accommodate different heights of light. The incubator is black to prevent stray light in optical experiments. This design can not only insulate but also debug optical or non-optical parts according working accuracy of parts. In this paper, an example incubator is used for an optical experiment was given and the incubator was optimized several times. The temperature fluctuations of the box of the third optimized incubator reached $0.045^{\circ} \mathrm{C}$. To reduce the temperature fluctuations, the relationship between the ambient and target temperature as well as the temperature fluctuations of the box were analyzed, and a formula was proposed. A further experiment provided evidence for this relationship. Based on the formula, the SLITA (small optimized incubator placed in large optimized incubator with the same target temperature) method for improving insulation accuracy was further proposed, and an incubator was designed using this method. The temperature fluctuations were $0.000014{ }^{\circ} \mathrm{C}$ by simulation, which was reduced $98.6 \%$ compared to previous incubators.
\end{abstract}

Keywords: combination incubator; adjustable light window; debugging platform; temperature fluctuations; optimized incubator; SLITA

\section{Introduction}

Reducing energy consumption and greenhouse gas emissions caused by growing industrialized economies is a problem worth studying. Many researchers have carried out studies on improvements in the greenhouse envelope and the reduction of associated greenhouse energy consumption. Wu et al., Pinto et al., Zhang et al., Al et al., and Gulfam et al. conducted research on greenhouse materials to reduce the energy loss of greenhouses and achieve energy savings of up to $34.6 \%$ [1-5]. The following researchers studied temperature control and proposed new ways to reduce energy consumption. Kazmi et al. proposed a multi-agent reinforcement learning framework for black-box modeling that could accelerate the learning of thermostatically controlled load behavior, thereby enabling fast active control. Efficiency gains of $20 \%$ were realized in a year [6]. Through experiments, Cholewa et al. concluded that the energy savings was between $7.1 \%$ and $23.3 \%$ depending on the range of modernization activities using thermostatic radiator valves [7]. Daffallah et al. recorded the power consumption of a refrigerator with different loads, compared these cases to that of power consumption without loading, and observed that the thermostat setting position has a considerable 
effect on the energy consumption of refrigerators [8]. Bomela et al. presented phase response based open-loop control policies that minimized power overshoots and allowed the integration of renewable energy sources [9]. Lan et al. focused on a dynamic model of a thermoelectric generator system designed for vehicle waste heat recovery and predicted that an average power output increase of approximately $20 \%$ could be obtained by optimizing the thermal contact conductance and the heat transfer coefficient of the hot side heat exchanger [10]. Chassin et al. designed a new control strategy for residential heating and cooling thermostats that supported the transactive control system concept, could operate in real-time distribution capacity auction systems, and facilitated the increased integration of renewable resources [11]. Shahzad et al. designed a user-controlled thermal office chair equipped with thermal control over the seat and backrest. The energy consumption of the thermal chair was relatively low $(0.03 \mathrm{~kW})$. The chair improved users' overall thermal comfort and further reduced energy consumption [12].

With the development of science and technology, the precision of incubators has become high. The National Institute of Standards and Technology designed a Molecular Measuring Machine. The room temperature was kept at $17^{\circ} \mathrm{C}$ to act as a heat sink, and the temperature fluctuations of the core were kept at $\pm 0.005^{\circ} \mathrm{C}$ for the target temperature of $20^{\circ} \mathrm{C}[13,14]$. The BUPE (Billionth Uncertainty Precision Engineering) in Korea designed the Ultra Precision CMM (three-coordinate measuring machine) with a strict multi-layer closed structure. The incubator's temperature fluctuations were $\pm 0.001{ }^{\circ} \mathrm{C}$ for the target temperature of $20^{\circ} \mathrm{C}$.

These studies have saved energy in industrialized economies and created high precision insulation incubators. At present, the operation of many components (such as precision machine tool spindles, optical ferro-elastic liquid crystals, liquid-crystal variable retarders, multi-order waveplates, medical equipment, nanotechnology, nanomanufacturing, and black-body radiation technologies) requires not only high-precision temperature distribution but also other functional requirements as well as higher precision temperature distribution to ensure better working accuracy and environments [15-17]. There is currently no device that meets these requirements. A device would need to have more than two types of functions to meet or it could not meet the job requirements.

In this paper, a new type of incubator is derived based on an existing greenhouse: a mini thermostatic chamber. This incubator saves energy while combining structures of different industrial fields to expand the function of the greenhouse.

A new structure is added to the original structure of the greenhouse to expand its function. The industrial use of the adjustment workbench is combined with the greenhouse so that it can ensure the high-precision work requirements of the components (e.g., coaxiality and angle) while maintaining the required operating temperature. The organ form rail machine guard shield is combined with the front and rear windows of the greenhouse to make the windows retractable with a certain airtightness. The retractability of the windows allows the incubator to meet different external light source requirements, and the airtightness of the windows provides insulation for the optical components, which ensures high-precision working requirements. The proposed optimized structure allows the incubator to ensure that high-precision non-optical parts and components for optical production work properly.

In order to obtain higher precision insulation incubator, the thickness of insulation layer of the incubator and the support columns structure of the incubator are optimized. Then, the relationship between the ambient temperature and the target temperature as well as the temperature fluctuations of the box were analyzed with ANSYS. A new formula was proposed. According to the formula and optimizing the structure of the large and small incubators by changing thickness of insulation layer, the SLITA (small optimized incubator placed in large optimized incubator with the same target temperature) method proposed in this paper caused the temperature fluctuations of the box to reach $0.000014{ }^{\circ} \mathrm{C}$ at $-10^{\circ} \mathrm{C}$, and a new ultra-precision incubator was obtained. This incubator achieved the minimum temperature fluctuations of the box. Many researchers have studied the relationship between the structures of tube and heat flux, Nusselt number, and temperature. Moraveji et al. investigated the 
effects of number of inlets, tube length, diameter of cold outlet on temperature, and flow rates passing through the vortex tube. The vortex tube is used to separate hot and cold gas streams from a higher pressure inlet gas stream [18]. Toghraie studied the effect of fluid jet velocity of water and subcooled temperature on the rewetting temperature, wet zone propagation, cooling rate, and maximum heat flux [19]. Hosseinnezhad et al. investigated the turbulent flow of water $/ \mathrm{Al}_{2} \mathrm{O}_{3}$ nanofluid in a tube with two twisted tape inserts with numerical simulation. They found the effect of the twist ratio, the counter-swirl flow twisted-tape, and the enhancement of volume fraction of $\mathrm{Al}_{2} \mathrm{O}_{3}$ nanoparticles in the base fluid on the amount of average Nusselt number [20]. Pourdel et al. investigated the fluid flow and heat transfer in a flat tube by simulation. They found that the presence of dimples on heat transfer surfaces highly affected the fluid flow physics [21]. Yang et al. built and tested an experimental model to analyze and optimize the heat loss associated with the household solar heating system. They identified the relationship between the wind speed, ambient temperature, the temperature of the heating water tank, and the indoor temperature. The result should help save energy [22]. This paper has studied the temperature fluctuations of the box of incubator, and the optimization results of the incubator are obtained by changing the material, thickness of insulation layer, and support columns structure. The relationship between the ambient temperature and the target temperature as well as the temperature fluctuations of the box were analyzed. An experiment was carried out, and its results supported those analyzed. The SLITA method was proposed by analyzing and obtaining the formula. A new ultra-precision incubator was obtained. This study is different from those studies, and it improved the accuracy of the incubator through simulation, experiment, and the resulting formula. This will make up for the gap in ultra-precision incubators.

\section{Methods}

\subsection{Overall Structure of Incubator}

The incubator comprises a support column, an installation and debugging platform fixed to the support column, and a box installed on the installation and debugging platform (shown in Figure 1). The box surrounds the installation and debugging platform. On both sides of the box, strip-shaped through-holes are provided with an adjustable light window. Sixteen temperature sensors are located inside the incubator, the heating and cooling parts are around the box, and the insulating layer is placed on the outside. The cooling parts, heating parts, and temperature sensors are connected to the controller; they are controlled to achieve the required operating temperature in the incubator. The device can be small, light, low cost, and universal, and it is not limited to the type of insulated object as long as the object can be placed in the incubator. Its inner surface area ranges from $2.4 \mathrm{~m}^{2}$ to $60 \mathrm{~m}^{2}$. The incubator is black to prevent the influence of stray light during optical experiments. In addition, the front and rear light windows of the box can be adjusted in height to meet different external light source requirements. Moreover, the incubator provides an installation and debugging platform for components.

\subsection{Characteristics of Each Structural Part}

\subsubsection{The Heating Part of the Incubator}

The incubator is heated by silicone rubber heating wires. Heating-wire materials can be constantan alloy, Kang Manganese copper alloy, or nichrome. These heating wires are wrapped around the glass fibers, and then silicone rubber insulation completely enwraps the wires. The silicone rubber heating wire is soft and easy to lay out; and it can be heated up to $60^{\circ} \mathrm{C}$. The silicone rubber heating wires are evenly arranged on the top and sides of the box, as well as at the bottom of the installation and debugging platform (shown in Figure 1). 


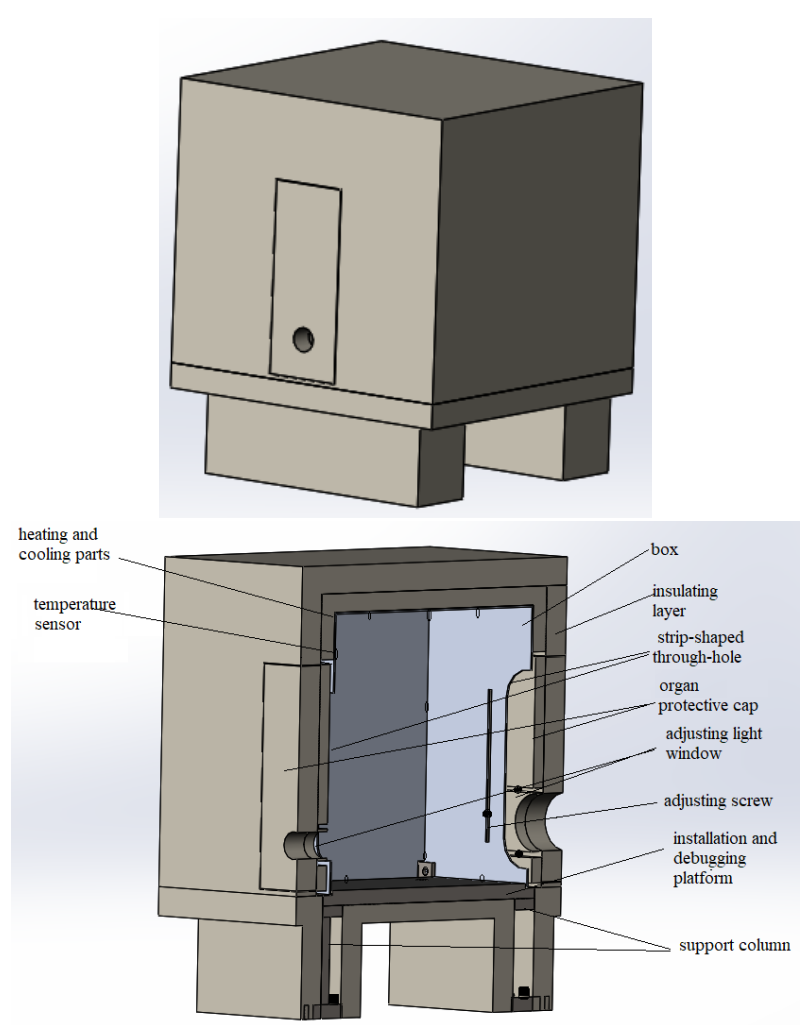

Figure 1. Main body of the incubator.

\subsubsection{The Cooling Part of the Incubator}

Semiconductor chilling plates or water-cooling devices cool the incubator. Semiconductor chilling plates are simple to install and operate. Their refrigeration efficiency is $\leq 60 \%$ and the maximum temperature difference can reach $67^{\circ} \mathrm{C}$. A fan provides a limited amount of heat dissipation for the semiconductor chilling plates, and water cooling can be used if the heat-dissipation requirements are large. The operation of the water-cooling device is complicated and requires a water source. The water-cooling device has a high cooling efficiency and can cool objects to $-15^{\circ} \mathrm{C}$. The device is uniformly distributed on the top and sides of the box, as well as at the bottom surface of the installation and debugging platform.

\subsubsection{The Adjustable Light Window}

The adjustable light window of the incubator is installed between an upper organ protective cap and a lower organ protective cap. In the center of the adjustable light window, there is a light through-hole. On the adjustable light window's left and right, the adjustment screws are installed in holes that are arranged on both sides of the box's strip through-holes. The adjustable light window moves up and down along the strip through-holes via the adjustment screws (shown in Figure 1).

An organ protective cap is used in the machine tool to prevent the high-precision work requirements of components from dust throughout components movement. The organ protective cap was used in the adjustable light window and its material was changed. The cap prevents dust and stray light from entering, but it cannot prevent a large amount of energy loss. Therefore, soft insulation was used for the cap. The soft insulation can prevent dust and stray light from entering, it can prevent a large amount of energy loss, and it is retractable (shown in Figure 2). 


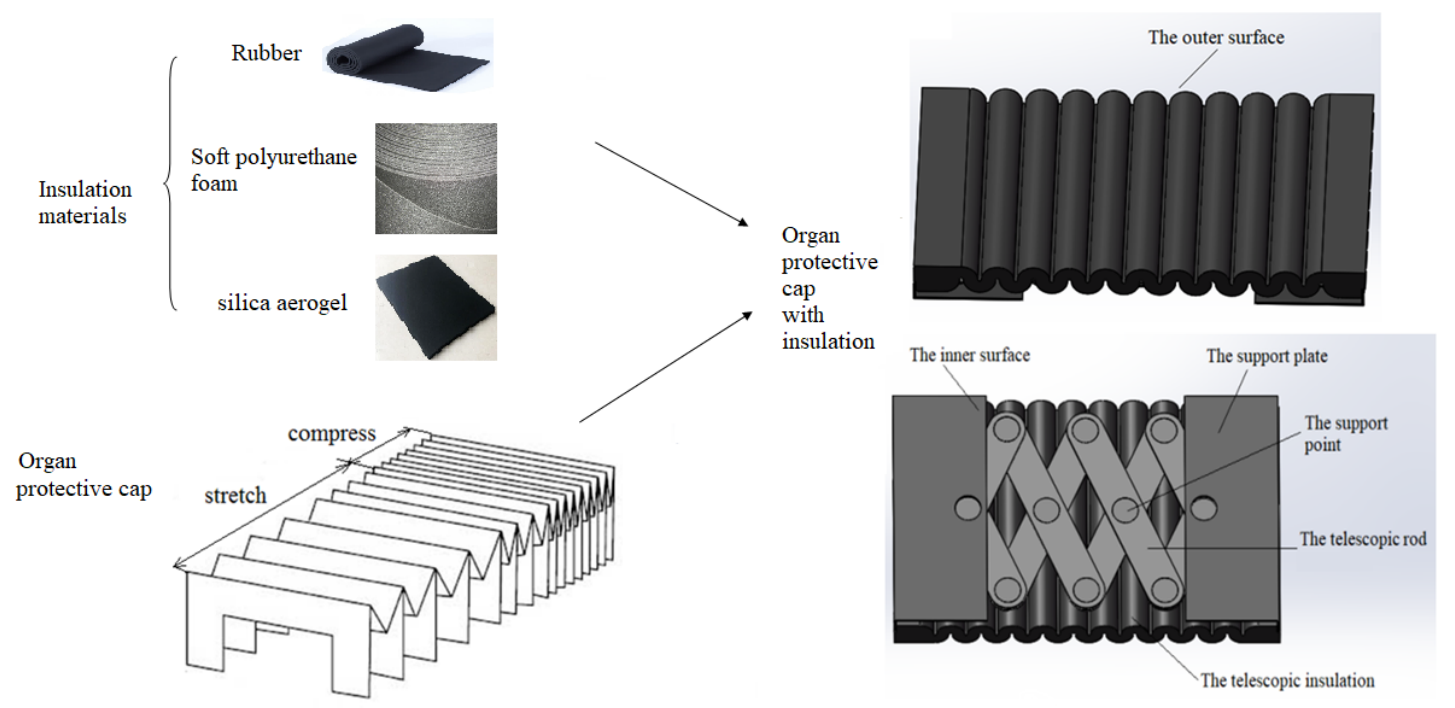

Figure 2. The synthesizing process of adjustable light window.

A light source can be positioned on one side of the incubator such that the light enters from the adjustable light window on one side of the box, passes through the optical element in the incubator, and is emitted from the adjustable light window on the other side of the box. The light through-hole (which is a threaded hole) is covered by a transparent cover. The transparent cover acts as a seal as well as a means to observe changes in the incubator through the light window. The transparent cover can be replaced with a black cover if observation is unnecessary.

\subsubsection{The Installation and Debugging Platforms}

Installation and debugging platforms of different precision levels can be selected according to the installation accuracy requirements. There are many mounting holes on the installation and debugging platform [23]. The optical table is implemented for installation and debugging of components. If it is used to test the performance of a component that affects the accuracy and surface of the installation and debugging platform, a protective plate must be placed on the installation and debugging platform, and then the component is placed on the protective plate. The platform does not require the protective plate in the case of experiments that do not affect its performance.

\subsubsection{The Insulation Layer of the Incubator}

Glass wool, rock wool, expanded polystyrene (EPS), extruded polystyrene (XPS), silica aerogel, vacuum insulation panel, or polyurethane foam can be used as the insulation material. The insulation layer of the incubator is used to prevent a large amount of energy loss, and to ensure that the required working temperature is efficiently achieved in the incubator [24-26]. The temperature fluctuations of the box can be controlled at $0.1^{\circ} \mathrm{C}$ or in even smaller increments, such as $0.09^{\circ} \mathrm{C}$, $0.045^{\circ} \mathrm{C}$, or $0.000014^{\circ} \mathrm{C}$.

\section{Specific Case}

This incubator is useful for ambient temperatures in the range of $-10^{\circ} \mathrm{C}$ to $40^{\circ} \mathrm{C}$ and can be used for $\leq 280 \mathrm{~mm} \times 280 \mathrm{~mm} \times 280 \mathrm{~mm}$ objects. The incubator weighs approximately $28.3 \mathrm{~kg}$. The incubator enables the optical path height to be adjusted in the range of $182-332 \mathrm{~mm}$ for insulation of the optical members. The installation and debugging platform is suitable for parts with high-precision requirements. The following is a case in which ferro-elastic liquid crystal (FLC) and liquid-crystal variable-retarder (LCVR) polarizers are used in a polarization experiment, which requires insulation and precision adjustment. The operating temperature of the FLC is $20-30^{\circ} \mathrm{C}$, and the 
operating-temperature accuracy must be controlled within $\pm 1^{\circ} \mathrm{C}$. The operating temperature of the LCVR is $-20^{\circ} \mathrm{C}$ to $45^{\circ} \mathrm{C}$, and the operating-temperature accuracy must be controlled within $\pm 0.1^{\circ} \mathrm{C}$. To ensure normal working conditions for the FLC and LCVR, the operating temperatures are set at $25 \pm 0.1^{\circ} \mathrm{C}$. This experiment requires the FLC and LCVR to be installed and adjusted to $0.2^{\circ}$ parallel to the mounting surface of the mounting platform.

\subsection{Overall Structure of the Incubator}

The structure of the incubator is shown in Figure 3a. Figure $3 b$ is a cross-sectional view of the incubator. The incubator is comprised of two support columns (8), an installation and debugging platform (7), a box (1), cooling parts (9), heating parts (2), temperature sensors (12), insulating layers (3), and a controller. The installation and debugging platform is installed on the support column. The box is hinged on the installation and debugging platform, and the box surrounds the installation and debugging platform. The strip-shaped through-holes on the front and back of the box are provided with adjustable light windows (5) (shown in Figure 3b). The heating and cooling parts are uniformly arranged on the outside of the box and at the bottom of the installation and debugging platform. Insulating layers surround the box and the installation and debugging platform. The temperature sensors are installed in the incubator, and the cooling and heating parts are connected to the controller. The box is hinged to the right-hand corner of the installation and debugging platform with two rivets (11) (shown in Figure 3b).

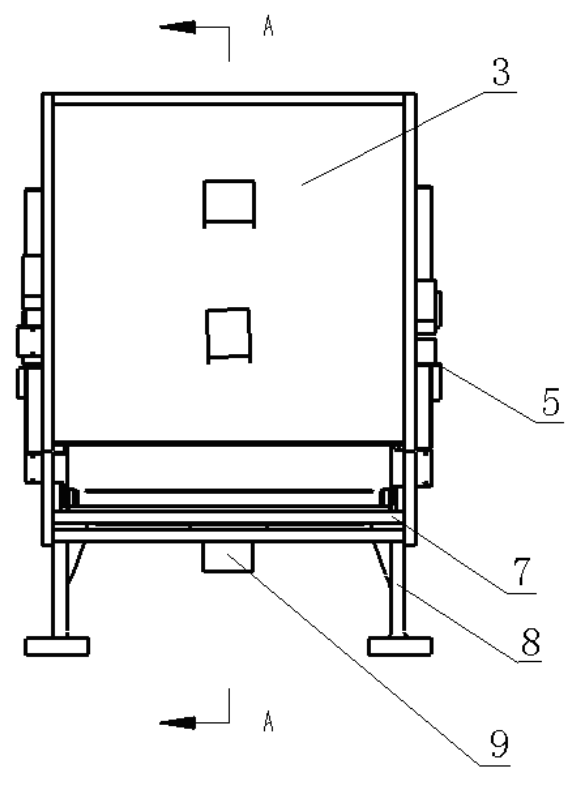

(a)

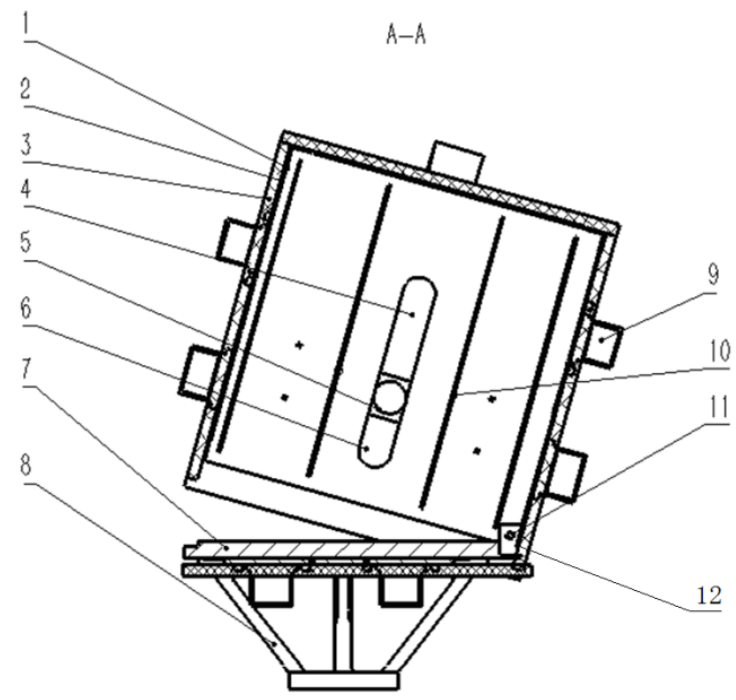

(b)

Figure 3. (a) main body of the incubator; (b) cross-sectional view of the incubator.

\subsection{Key Technologies and Features}

\subsubsection{The System of the Adjustable Light Window}

The upper and lower organ protective caps on the front and rear of the incubator are elastic organ protective caps. The system for the front adjustable light window on the box includes the upper organ protective cap (4), the lower organ protective cap (6), and the adjustable light window with a light-passing hole installed between the upper organ protective cap and the lower organ protective cap (shown in Figure 3b). The front adjustable light window moves up and down along the strip through-hole by adjusting screws (10). The rear adjustable light window on the box has the same structure. The adjustable light window is adjusted by screws sliding in the chutes on both sides of the 
strip through-hole to make it well-connected to the external light source. After adjusting the height of the light window, the window can be fixed by tightening the screws. The range of the adjustable height is $182-332 \mathrm{~mm}$.

A light source will be placed in front of the incubator if an external light source is required. The light source could be laser light or white light. When the adjustable light window is connected to the external light source, the light enters the window in front of the incubator, passes through the optical elements in the incubator, and is emitted from the other adjustable light window in the back of the incubator. The incubator is black to help prevent stray light.

The light through-hole (which is a threaded hole) in the adjustable light window will be covered by a transparent cover. The transparent cover not only acts as a seal, but also allows observations of the incubator's interior. The transparent cover can be replaced with a black cover if observation is not required.

\subsubsection{The Heating and Cooling Parts}

The incubator is cooled by semiconductor chilling plates. They are uniformly distributed on the top and the sides of the box and at the bottom of the installation and debugging platform. The incubator is heated by heating wires. They are evenly arranged on the top and the sides of the box and at the bottom of the installation and debugging platform.

The temperature sensors arranged in the incubator are German Heraeus PT100s. The temperature measurement accuracy is $\pm 0.1^{\circ} \mathrm{C}$. The controller is a digital proportion integration differentiation thermostat controller AT704 that sets the required working temperature, such as $25^{\circ} \mathrm{C}$.

When the required working temperature is higher than the external ambient temperature, heating wires are used to heat the box to $25^{\circ} \mathrm{C}$. When the temperature sensors detect the temperature in the incubator lower than $25^{\circ} \mathrm{C}$, the heating power value of the heating wires is increased by the controller to heat the incubator. When the temperature sensors detect that the temperature in the incubator is higher than $25^{\circ} \mathrm{C}$, the heating power value of the heating wires is reduced by the controller.

When the required working temperature is lower than the external ambient temperature, the semiconductor chilling plates are used to cool the incubator and reach $25^{\circ} \mathrm{C}$. When the temperature sensors detect that the temperature in the incubator is higher than $25^{\circ} \mathrm{C}$, the cooling power of the semiconductor chilling plates is increased by the controller to cool the incubator. When the temperature sensors detect that the temperature in the incubator is lower than $25^{\circ} \mathrm{C}$, the cooling power of the semiconductor chilling plates is reduced by the controller to cool the incubator. Finally, the incubator will reach the target value of $25 \pm 0.1^{\circ} \mathrm{C}$.

\subsubsection{The Installation and Debugging Platform}

There are many threaded mounting holes on the installation and debugging platform. The tool and fixture are installed on the installation and debugging platform to adjust the components to be tested in order to analyze their characteristics. The size of the installation and debugging platform is $320 \mathrm{~mm} \times 309 \mathrm{~mm} \times 50 \mathrm{~mm}$, the flatness of the top skin is $<0.05 \mathrm{~mm} / \mathrm{m}^{2}$, the surface roughness is $<0.8 \mu \mathrm{m}$, and the payload capacity is $800 \mathrm{~kg} / \mathrm{m}^{2}$. This precision platform could be bought or made.

If the incubator is used to test the performance of a component that affects the accuracy and surface of the platform, a protective plate must be placed on the platform, and then the component is placed on the protective plate. The platform does not require the protective plate in the case of experiments that do not affect its performance.

\subsubsection{The Insulation Layer}

The insulation layer of the incubator is polyurethane foam. The density of the polyurethane foam is approximately $35 \mathrm{~kg} / \mathrm{m}^{3}$, and the thermal conductivity is approximately $0.027 \mathrm{~W} /(\mathrm{m} \cdot \mathrm{K})$. Insulation layers are arranged on the top and side of the box and at the bottom of the platform to prevent a 
large amount of energy loss and ensure that the required working temperature is achieved in the incubator efficiently.

\subsubsection{Incubator Switch}

The box is hinged to the right corner of the platform by two rivets (shown in Figure $3 b$ ). The size of the box is $300 \mathrm{~mm} \times 300 \mathrm{~mm} \times 300 \mathrm{~mm}$. If necessary, the box could be opened to expose the components directly. After the box is opened, it is directly supported on one side of the platform without removing the box, which is convenient and reliable. When the box is closed, the components are enclosed in the incubator, which can prevent the interference of stray light in the optical experiment, reduce the energy loss when heating or cooling the incubator, and contribute to the stability of the temperature inside the incubator. A door can be created on the left side of the box, which is convenient for placing parts inside the incubator (shown in Figure 3b).

\subsection{Optical Parts FLC and LCVR Insulation Methods}

(1) The desired light source is placed on the front side of the incubator directly opposite the front light window. As shown in Figure 3b, the front side light window can be adjusted according to the height of the light source so that the light goes into the incubator.

(2) The box is opened and directly supported on one side of the platform. The FLC and LCVR that need to be insulated are placed on the platform for light path adjustment $[27,28]$. The FLC and LCVR are installed and adjusted to be $0.1^{\circ}$ parallel to the mounting surface of the mounting platform. Adjustment of the optical path is finished and then the box is covered just above the platform.

(3) The rear light window is adjusted according to the height of the light transmission so that the light in the incubator passes through the rear light window. Then, the light passes through the optical element and the detection instrument outside the incubator.

(4) According to the working temperature requirements of the optical components in the incubator, the incubator is either heated or cooled. At the same time, the temperature sensors detect the temperature value in the incubator and then feed the information back to the electronic control system for correcting heating or cooling. Finally, the target temperature in the incubator is reached.

(5) After the optical path and working temperature are adjusted, the working performance and the characteristics of the optical components are analyzed to obtain the final result.

\subsection{Analyzing Temperature Distribution of the Box and Optimizing the Incubator}

The working temperature of FLC and LCVR is $25 \pm 0.1^{\circ} \mathrm{C}$. The box is made of $6 \mathrm{~A} 02$ aluminum alloy. The platform and support column are made of steel. The heating wire is made of constantan with a diameter of $0.5 \mathrm{~mm}$. Its resistivity is $2.44 \Omega / \mathrm{m}$ and its density is $8.9 \mathrm{~g} / \mathrm{cm}^{3}$. The heating power of the heating wire is given by:

$$
\varphi=\Delta t / R=\left(t_{f 1}-t_{f 2}\right) / \Sigma R_{i}=\left(t_{f 1}-t_{f 2}\right) /\left[\left(1 / h_{1}+\delta_{1} / \lambda_{1}+\delta_{2} / \lambda_{2} \ldots+\delta_{i} / \lambda_{i}+1 / h_{2}\right) \times 1 / A\right]
$$

where $\varphi$ is the heat transfer of $\mathrm{n}$ layers of the flat wall, $t_{f}$ is the fluid temperature on the solid surface, $\mathrm{h}$ is the surface heat transfer coefficient, $\delta$ is the thickness of the solid, $\lambda$ is the thermal conductivity of the solid, as shown in Figure 4, and A is the heat transfer surface area of the solid.

$$
h=N_{u} \times \lambda / l
$$

Free convection in large space [29]:

$$
\begin{gathered}
N_{u}=C \times\left(G_{r} \times P_{r}\right)^{n}, \\
G_{r}=g \times \alpha \times \Delta t \times(l)^{3} /(v)^{2},
\end{gathered}
$$


where $N_{u}$ is the Nusselt number, $l$ is the characteristic length, $G_{r}$ is the Grashof number, $P_{r}$ is the Prandtl number, $\alpha$ is the volume expansion coefficient, and $v$ is the kinematic viscosity.

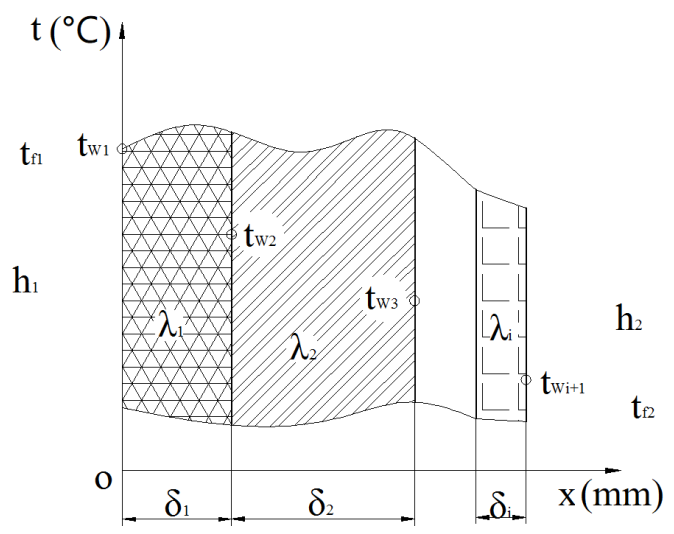

Figure 4. Heat transfer in a multi-layer wall.

The temperature distribution of the incubator is simulated by finite-element analysis software (ANSYS) [30]. First, a 3D model of incubator is established in computer aided design (such as SOLIDWORKS). The thickness of insulation layer is set as a parameter. Then, the 3D model is imported into ANSYS, in which the thickness of optimization variable insulation layer is parameterized. The characteristics of material of the insulation layer, box, installation, and debugging platform, support columns and other parts of incubator are set according to the actual use and production situation. The natural convection air, the required ambient temperature, and heating load of the incubator are set. The minimum value of the temperature difference between the highest and the lowest on the box is set as the optimization target. According to the above formula, the shape of the object, the value of $h$ is calculated preliminarily. The preliminary results of the temperature distribution in a steady state are obtained, and then $\mathrm{h}$ and $\varphi$ are corrected until the temperature distribution is obtained within the error range [31,32].

For the light window part and for the case of guaranteed light transmission, it is necessary to use a vacuum flat glass cover to isolate the air convection between the inside and outside of the box and to reduce the temperature fluctuations of the box. The incubator meshing was set based on the quality requirements of the analysis. The mesh quality was checked using the SKEWNESS function in ANSYS, with values between 0 and 1 . SKEWNESS outputs 0 for the best mesh quality and 1 for the worst, and a mesh quality of $0.95-1$ is unacceptable. The calculation results of temperature difference between the highest and the lowest on the box could be accurate to 10th place after the decimal point, which fully met the required accuracy of calculations. The incubator mesh met the mesh quality requirement (shown in Figure 5a). By simulating the temperature of the initial structure of the incubator for an ambient temperature of $-10^{\circ} \mathrm{C}$, the temperature distribution of the box is as shown in Figure $5 \mathrm{~b}$. The temperature of the box was between $25.104^{\circ} \mathrm{C}$ and $16.707^{\circ} \mathrm{C}$, and the temperature fluctuations of the box reached $8.397^{\circ} \mathrm{C}$, was higher than the required $\pm 0.1^{\circ} \mathrm{C}$. The large temperature deviation was due to the support columns that extended out of the box (shown in Figure 6). The support columns were replaced by vacuum columns with adequate stiffness. The material of this vacuum column was cement. The thermal conductivity was $0.72 \mathrm{~W} /(\mathrm{m} \cdot \mathrm{K})$. The thickness of the insulation layer was the design variable and the minimum temperature fluctuations of the box comprised the objective function. The optimization result was obtained by changing the value of the design variable using a genetic algorithm. After optimization, the temperature of the box was between $25.456^{\circ} \mathrm{C}$ and $25.015^{\circ} \mathrm{C}$ (shown in Figure 7). The temperature fluctuations of the box reached $0.441^{\circ} \mathrm{C}$, which was higher than the required $\pm 0.1^{\circ} \mathrm{C}$.

The thermal conductivity of the vacuum was very low. A vacuum was used between the insulation layer and the wall of the box to reduce the exchange of energy between the outside and inside of the 
box. This further improved the thermal stability of the box and reduced its temperature fluctuations. The structure optimized by the genetic algorithm was obtained by changing the vacuum gap (shown in Figure 8). The temperature of the box was between $25.02^{\circ} \mathrm{C}$ and $24.93^{\circ} \mathrm{C}$, and the temperature fluctuations were within $0.09^{\circ} \mathrm{C}$, thus meeting the requirement of $\pm 0.1^{\circ} \mathrm{C}$.
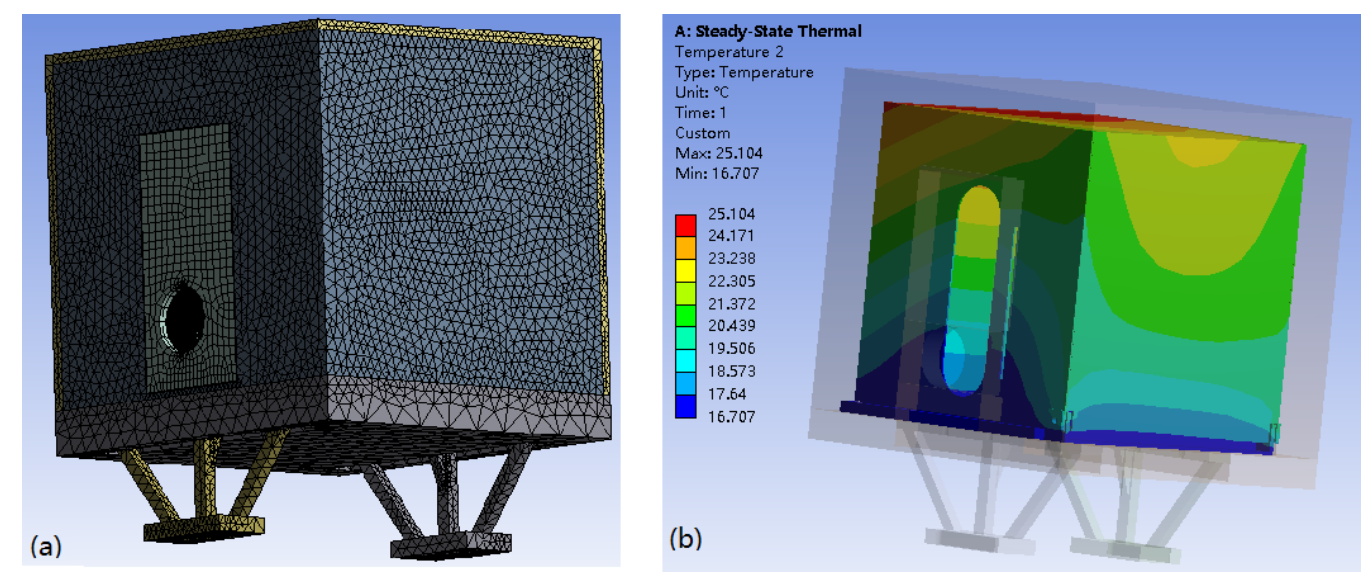

Figure 5. (a) meshed overall structure and (b) temperature distribution of the box and support column.

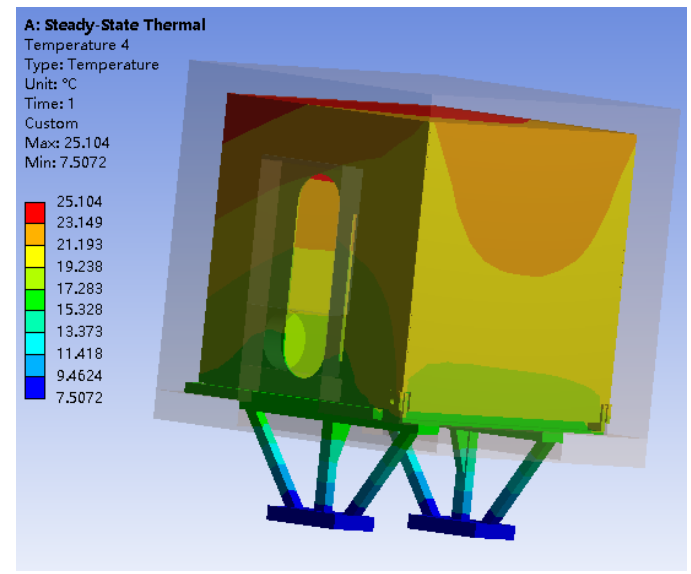

Figure 6. Temperature distribution of the box and support column.

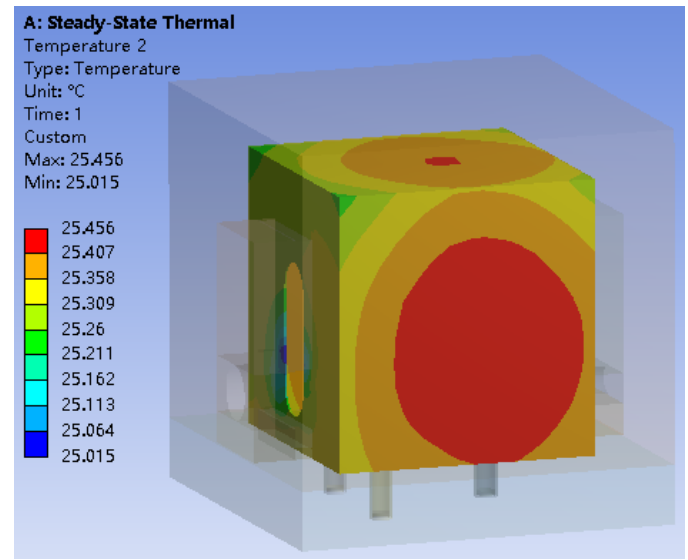

Figure 7. Temperature distribution of the simplified support column. 


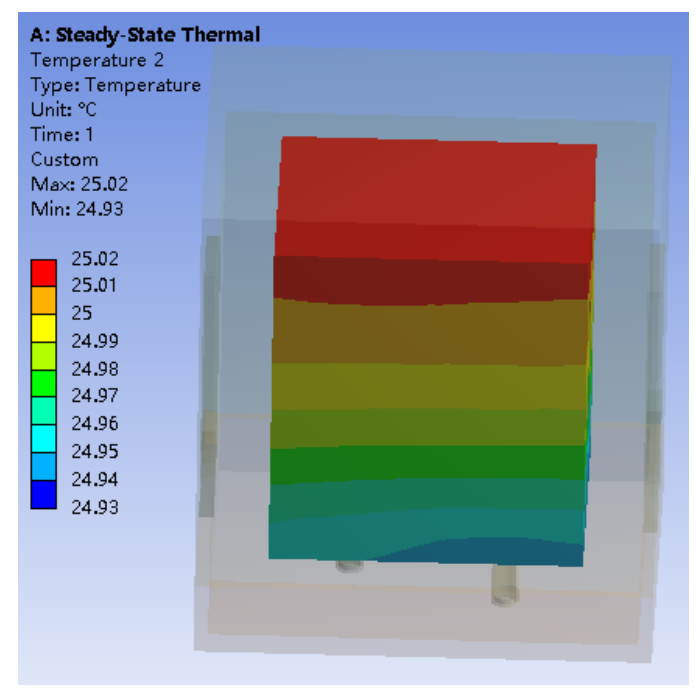

Figure 8. Temperature distribution of the box with the vacuum gap.

The vacuum insulation panel had a fairly low thermal conductivity, reaching $0.002-0.004 \mathrm{w} / \mathrm{m} / \mathrm{K}$, which was $1 / 10$ the thermal conductivities of traditional insulation material that their thermal conductivities were $0.012-0.05 \mathrm{w} / \mathrm{m} / \mathrm{K}$ such as polyurethane foam, Glass wool, rock wool, expanded polystyrene board, and silica aerogel. The thermal conductivity of the vacuum insulation panel selected for the incubator was $0.003 \mathrm{w} / \mathrm{m} / \mathrm{K}$. This incubator was similar to the incubator shown in Figure 7 , but the insulation layer of the polyurethane foam was replaced with the vacuum insulation panel. The thickness of the vacuum insulation panel used in this incubator was changed, and the optimization result was obtained with a genetic algorithm (shown in Figure 9). The temperature of the box was between $25.07^{\circ} \mathrm{C}$ and $-25.025^{\circ} \mathrm{C}$. The temperature fluctuations of the box were $0.045^{\circ} \mathrm{C}$, which were smaller than the fluctuations of the boxes of previous incubators.

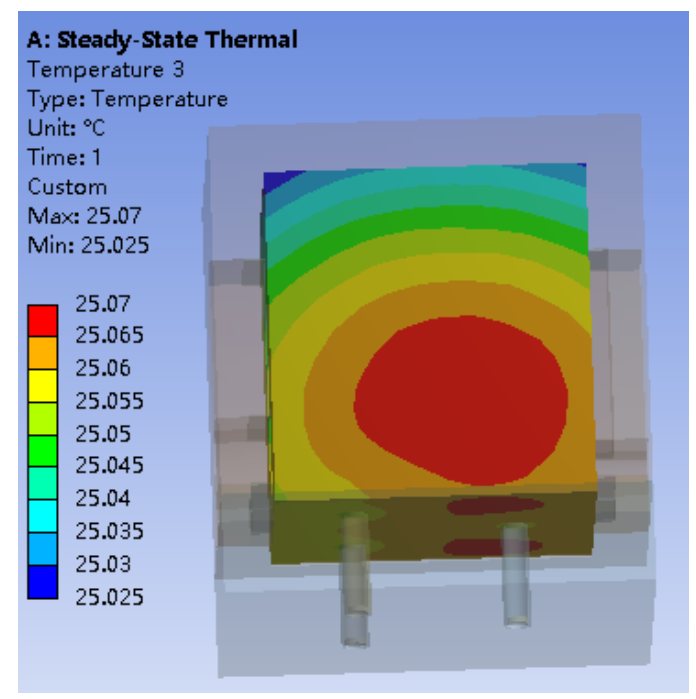

Figure 9. Temperature distribution of the box with vacuum insulation panels.

\subsection{The Influence of the Difference between the Environment and the Target Temperature}

The optimized structures described above were the result of simulations at an extreme ambient temperature of $-10{ }^{\circ} \mathrm{C}$, and the relationship between the ambient temperature and the target temperature as well as the temperature fluctuations of the box was assessed. First, different ambient temperatures for the optimized incubator (shown in Figure 7) with the insulation layer of polyurethane foam were set to $-5^{\circ} \mathrm{C}, 0^{\circ} \mathrm{C}, 5^{\circ} \mathrm{C}, 10^{\circ} \mathrm{C}, 15^{\circ} \mathrm{C}, 20^{\circ} \mathrm{C}, 22^{\circ} \mathrm{C}, 23^{\circ} \mathrm{C}, 26^{\circ} \mathrm{C}, 27^{\circ} \mathrm{C}$, 
$30^{\circ} \mathrm{C}, 35^{\circ} \mathrm{C}, 40^{\circ} \mathrm{C}, 45^{\circ} \mathrm{C}, 50^{\circ} \mathrm{C}, 55^{\circ} \mathrm{C}$, and $60^{\circ} \mathrm{C}$. The appropriate hot or cold flow was adjusted at the respective ambient temperature to bring the temperature distribution of the box to the same target value of $25^{\circ} \mathrm{C}$. The temperature fluctuations of the box were obtained at different ambient temperatures. The relationship between the ambient temperature and the target temperature as well as the temperature fluctuations of the box was linear (shown in Figures 10 and 11). Figures 10 and 11 showed that this relationship was $c=0.0182 \mathrm{I} \mathrm{a} \mid$. The $\mathrm{a}$ is the difference between the ambient temperature and the target temperature and its unit is ${ }^{\circ} \mathrm{C}$. The $\mathrm{c}$ is the temperature fluctuations of the box and its unit is ${ }^{\circ} \mathrm{C}$. In Figures 10-22, the " $\circ$ " represents the results at different a by simulation, these points " $\circ$ " are fitted into straight lines by the least square method, and the " $\star$ " represents results at different a on the lines. When the target temperature was $10^{\circ} \mathrm{C}$, the relationship between the ambient temperature and the target temperature as well as the temperature fluctuations of the box was linear (shown in Figures 12 and 13). The relationship between a and c was obtained as:

$$
c=0.0182|a|
$$

For the same incubator, when the target temperature was different, as long as the absolute value of the difference between the ambient temperature and the target temperature was the same, the temperature fluctuations of the box were the same.

When the insulation layer was a vacuum insulation panel, the relationship between the ambient temperature and the target temperature as well as the temperature fluctuations of the box was linear (shown in Figures 14 and 15). Figures 14 and 15 showed that the relationship was achieved through points and obtained as $\mathrm{c}=0.0013 \mathrm{I} \mathrm{a} \mathrm{I}$. When the target temperature was $10^{\circ} \mathrm{C}$, the relationship was linear (shown in Figures 16 and 17) and obtained as:

$$
c=0.0013|a|
$$

From the above simulation results, the relationship between the ambient temperature and the target temperature as well as the temperature fluctuations of the box showed a good linearity. For the same incubator, when the target temperature was different, as long as the absolute value of the difference between ambient temperature and the target temperature was the same, the temperature fluctuations of the box were the same. Additionally, the relationship between the ambient temperature and the target temperature as well as the temperature fluctuations of the box remained the same. Because the heat exchange area of the same incubator does not change, its heat transfer performance does not change, and the relationship between a and c remains unchanged. Therefore, the heat exchange of the structure of the incubator is unchanged as long as $|a|$ was the same, and the temperature fluctuations of the box subsequently remains unchanged.

If the material used in the insulation layer is changed, the relationship between the ambient temperature and the target temperature as well as the temperature fluctuations of the box will vary. Because different insulation layer materials have different thermal conductivities and their heat transfer performance varies, the heat exchange of the incubator structure will change, even for the same structure size, and the temperature fluctuations of the box will change. The lower the difference between the ambient temperature and the target temperature is, the smaller the heat exchange of the incubator structure, and the smaller the temperature fluctuations of the box. 


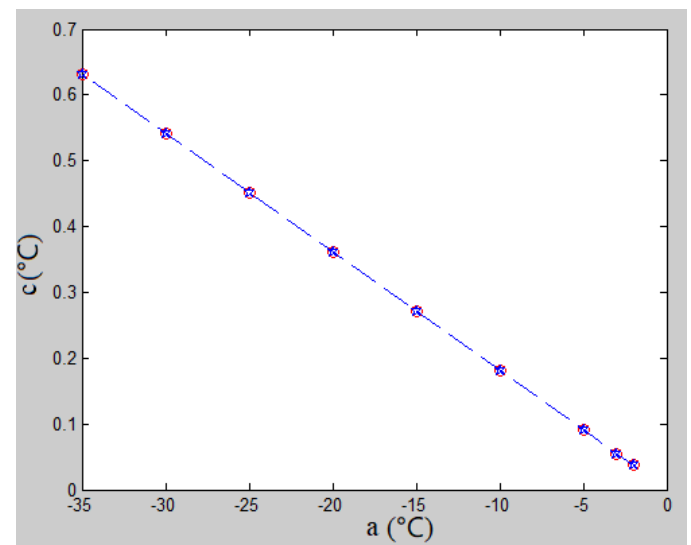

Figure 10. Effect of a on c below $25^{\circ} \mathrm{C}$ with polyurethane foam. The a is the difference between the ambient temperature and the target temperature. The $\mathrm{c}$ is the temperature fluctuations of the box. The " $\circ$ " represents the results at different a by simulation. The " $\star$ " represents results at different a on the lines.

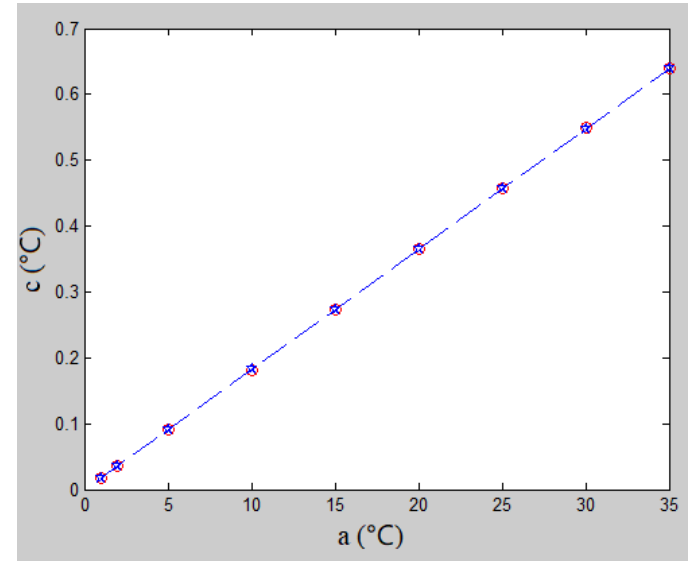

Figure 11. Effect of a on c above $25^{\circ} \mathrm{C}$ with polyurethane foam. The a, c, "o", and " $\star$ " have the same meaning as Figure 10.

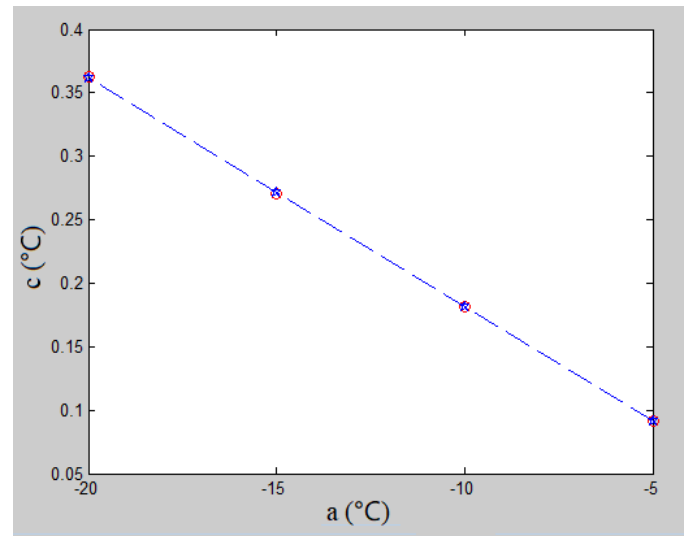

Figure 12. Effect of a on c below $10^{\circ} \mathrm{C}$ with polyurethane foam. The a, c, "o", and " $\star$ " have the same meaning as Figure 10. 


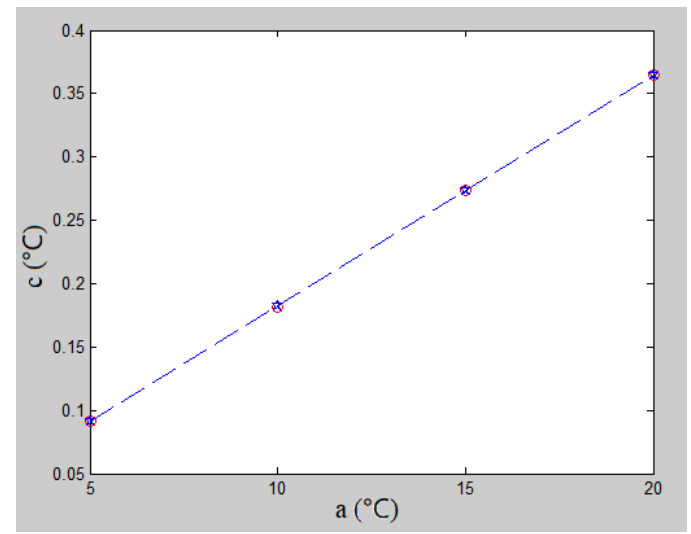

Figure 13. Effect of a on $\mathrm{c}$ above $10^{\circ} \mathrm{C}$ with polyurethane foam. The a, c, "o", and " $\star$ " have the same meaning as Figure 10.

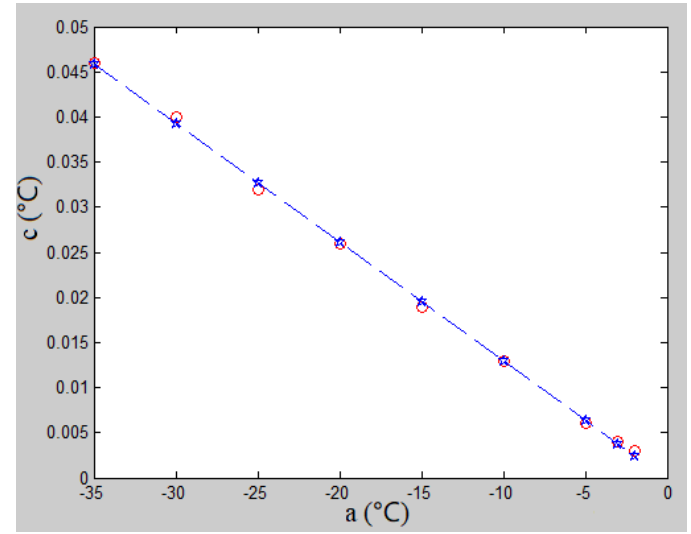

Figure 14. Effect of a on c below $25^{\circ} \mathrm{C}$ with vacuum insulation panel. The a, c, "o" and " $\star$ " have the same meaning as Figure 10.

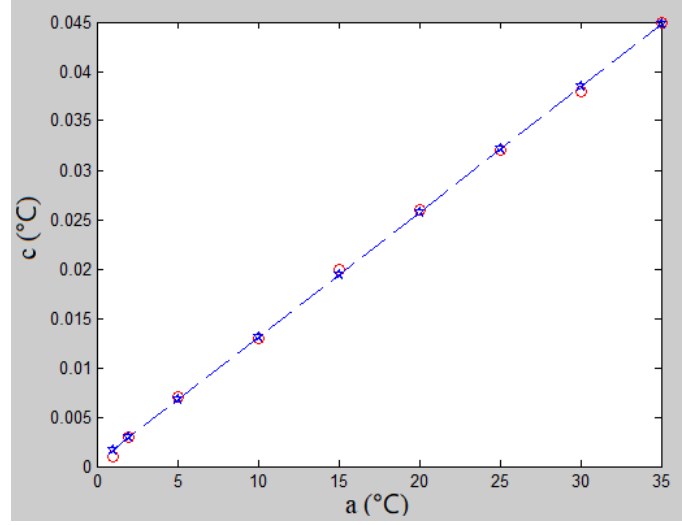

Figure 15. Effect of a on c above $25^{\circ} \mathrm{C}$ with vacuum insulation panel. The a, c, "o", and " $\star$ " have the same meaning as Figure 10. 


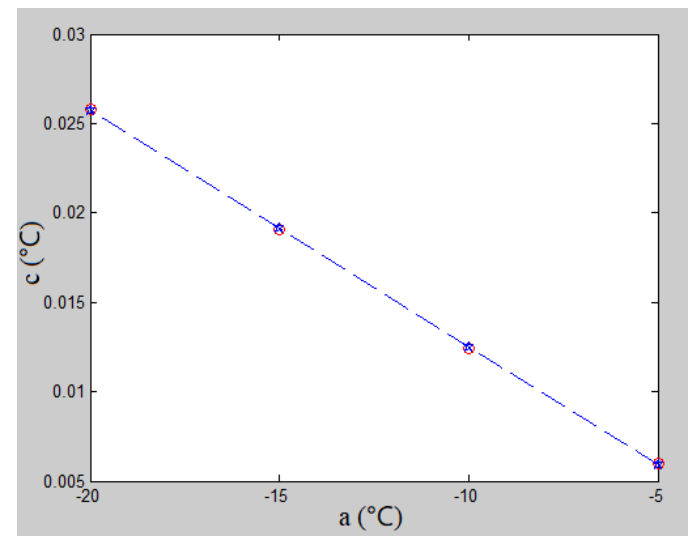

Figure 16. Effect of a on c below $10^{\circ} \mathrm{C}$ with vacuum insulation panel. The a, c, "॰", and " $\star$ " have the same meaning as Figure 10.

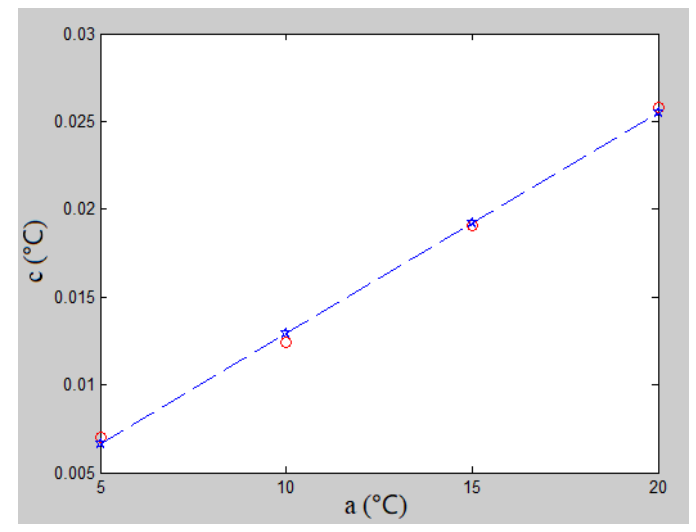

Figure 17. Effect of a on c above $10{ }^{\circ} \mathrm{C}$ with vacuum insulation panel. The a, c, "॰", and " $\star$ " have the same meaning as Figure 10.

Using the simplified incubator structure (shown in Figure 18a), the relationship between the ambient temperature and target temperature as well as the temperature fluctuations of the box was influenced by the volume of the incubator. The insulation layer was a vacuum insulation panel. The thickness of insulation layer was $30 \mathrm{~mm}$. Different ambient temperatures were set to $5^{\circ} \mathrm{C}$, $10^{\circ} \mathrm{C}, 15^{\circ} \mathrm{C}, 20^{\circ} \mathrm{C}, 30^{\circ} \mathrm{C}, 35^{\circ} \mathrm{C}, 40^{\circ} \mathrm{C}$, and $45^{\circ} \mathrm{C}$. The heating or cooling of the box was adjusted to reach the target temperature of $25^{\circ} \mathrm{C}$. The highest temperature was $25.032^{\circ} \mathrm{C}$ and the lowest temperature was $25.024^{\circ} \mathrm{C}$ on the $200 \times 200 \times 200 \mathrm{~mm}$ box at the extreme ambient temperature of $45^{\circ} \mathrm{C}$. The temperature distribution of this box at this extreme ambient temperature was shown in Figure 18b. After the simulations, the relationship between the ambient temperature and the target temperature as well as the temperature fluctuations of the boxes was obtained for $200 \times 200 \times 200 \mathrm{~mm}$ and $300 \times 300 \times 300 \mathrm{~mm}$ boxes (shown in Figures 19-22). Figure 19 and 20 showed that the relationship for the $200 \times 200 \times 200 \mathrm{~mm}$ box was:

$$
c=0.0004|a|
$$

From Figures 21 and 22, the relationship for the $300 \times 300 \times 300 \mathrm{~mm}$ box was:

$$
c=0.00055|a|
$$

When the size of the box changed, the coefficient of the relationship between the ambient temperature and the target temperature as well as the temperature fluctuations of the box also changed. Because the heat exchange area changed, the heat exchange of the incubator also changed as long as the material of the insulation layer was the same, and the temperature fluctuations of the box changed. 
A

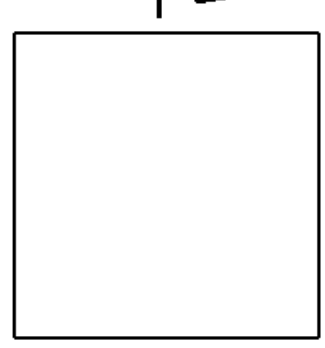

A
$\mathrm{A}-\mathrm{A}$

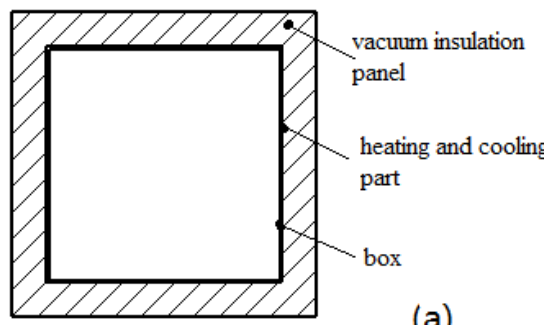

(a)

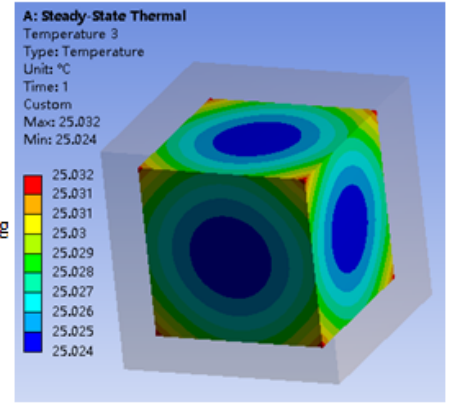

(b)

Figure 18. (a) Main body of the simplified incubator and (b) temperature distribution of the $200 \times 200 \times 200 \mathrm{~mm}$ box at the extreme ambient temperature of $45^{\circ} \mathrm{C}$.

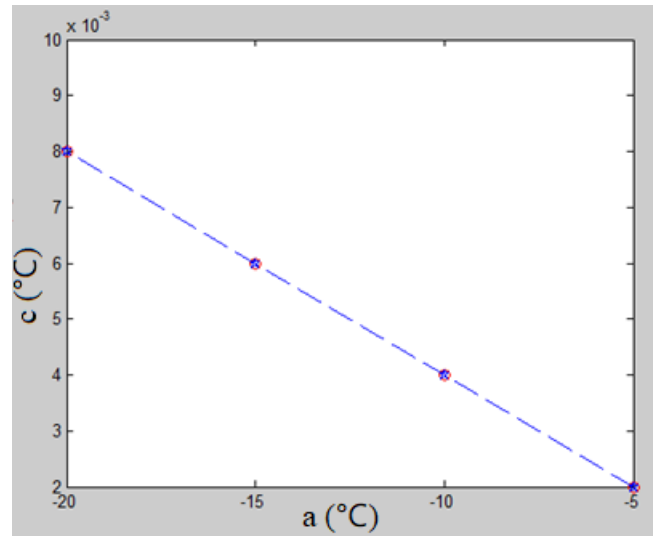

Figure 19. Effect of a on c below $25^{\circ} \mathrm{C}$ for $200 \times 200 \times 200 \mathrm{~mm}$ box. The a, c, “o", and " $\star$ " have the same meaning as Figure 10.

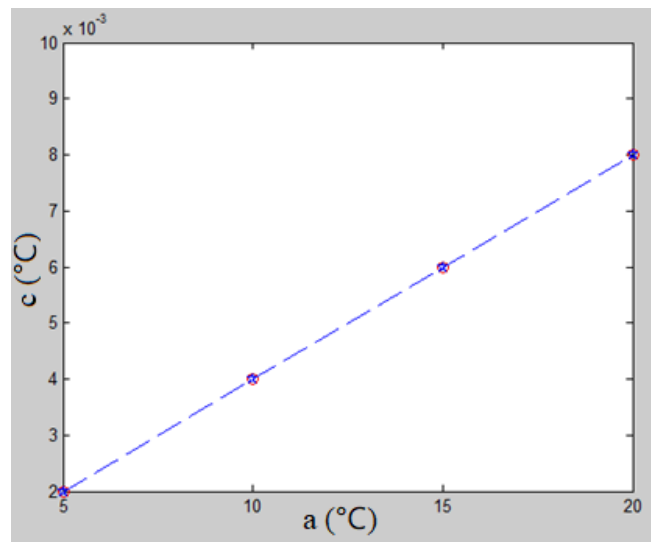

Figure 20. Effect of a on c above $25^{\circ} \mathrm{C}$ for $200 \times 200 \times 200 \mathrm{~mm}$ box. The a, c, “o", and " $\star$ " have the same meaning as Figure 10.

In the laboratory, the LCVR and FLC polarization tests were carried out. This incubator was the same as the incubator shown in Figure 5, and the insulation layer's thickness was $20 \mathrm{~mm}$. The ambient temperature was about $23^{\circ} \mathrm{C}$. The temperature of the box was between $25.001{ }^{\circ} \mathrm{C}$ and $24.902^{\circ} \mathrm{C}$ in the simulation. The temperature fluctuations of the box were $0.099^{\circ} \mathrm{C}$ and the fluctuations reached $\pm 0.1^{\circ} \mathrm{C}$ (shown in Figure 23). The temperature in the incubator was controlled at $25 \pm 0.1^{\circ} \mathrm{C}$ (shown in Figure 24) [33]. The incubator was not optimized in this experiment, but its temperature fluctuations for the box reached $\pm 0.1{ }^{\circ} \mathrm{C}$ easily because of the ambient temperature of $23^{\circ} \mathrm{C}$, which was close to $25^{\circ} \mathrm{C}$. 


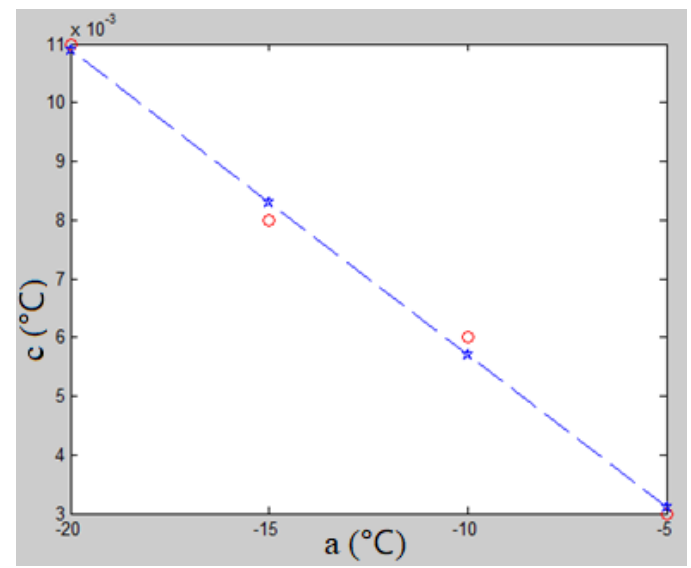

Figure 21. Effect of a on c below $25^{\circ} \mathrm{C}$ for $300 \times 300 \times 300 \mathrm{~mm}$ box. The a, c, "o", and " $\star$ " have the same meaning as Figure 10.

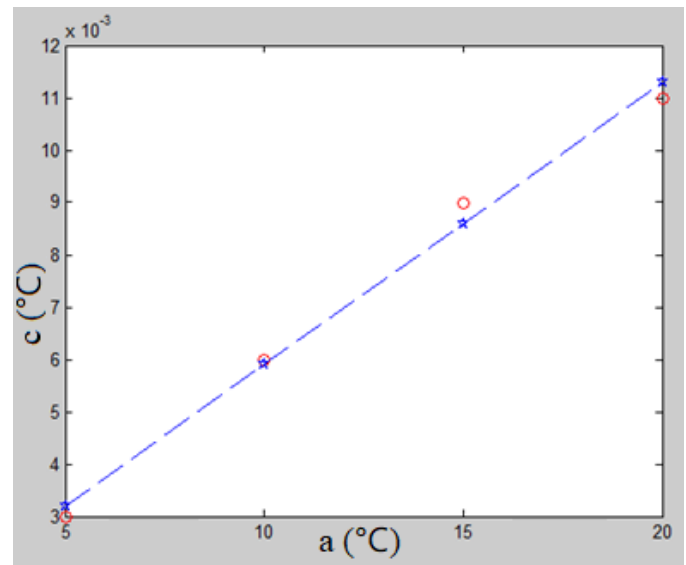

Figure 22. Effect of a on c above $25^{\circ} \mathrm{C}$ for $300 \times 300 \times 300 \mathrm{~mm}$ box. The a, c, “०", and " $\star$ " have the same meaning as Figure 10.

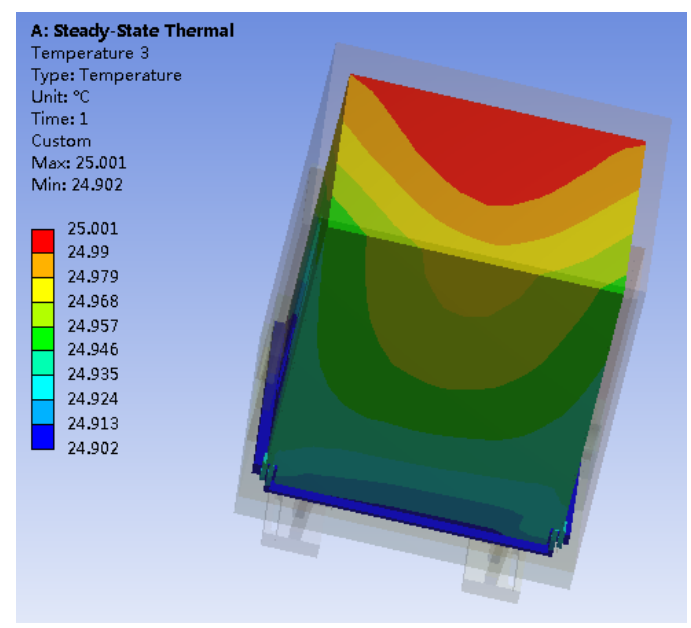

Figure 23. Temperature distribution of the box at $23^{\circ} \mathrm{C}$. 


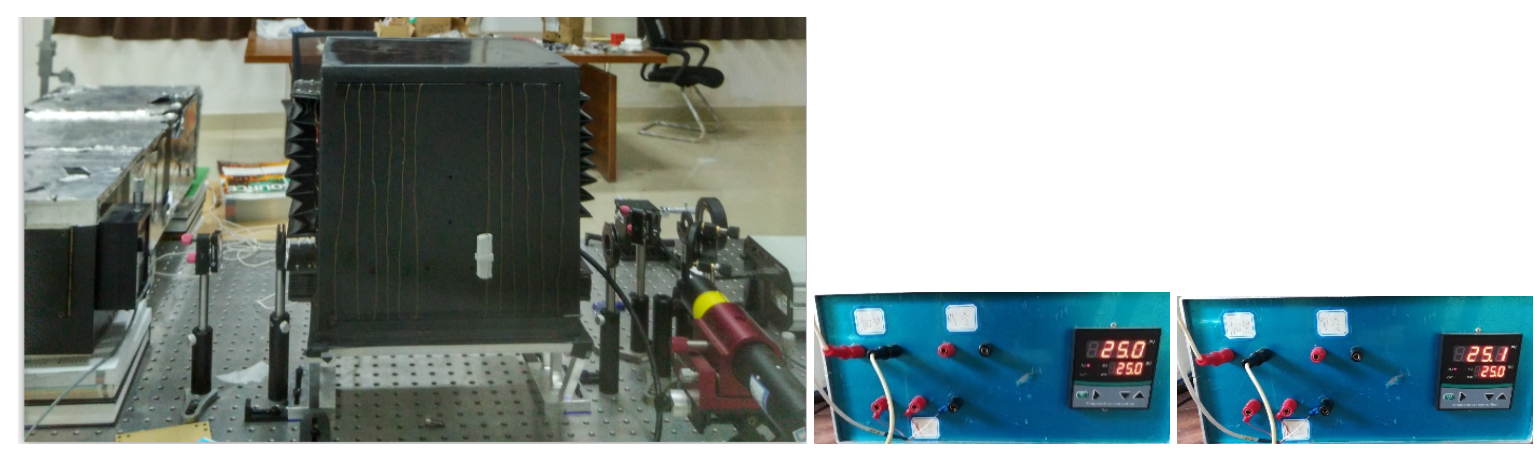

Figure 24. Constant-temperature experiment on LCVR and FLC.

\subsection{Improving the Insulation Accuracy Method}

According to the simulation results described in the previous section, when the ambient temperature was close to the target temperature, the temperature fluctuations of the box were smaller. Therefore, using a large incubator provides an ambient temperature that is close to the target temperature of the small incubator, which will greatly reduce the temperature fluctuations of the box of the small incubator. The improvements to the insulation accuracy method were as follows.

First, the structure of the small incubator is optimized. The thickness of the insulation layer is the design variable and the minimum temperature fluctuations of the box is the objective function. The optimization result is obtained by changing the value of the design variable using a genetic algorithm. Then, the small optimized incubator is expanded to a large incubator so that the small incubator can be placed in the large incubator. The target temperatures for the large incubator and the small incubator are the same. The structure of the large incubator is optimized, and the optimization method is the same as that of the small incubator, so the temperature fluctuations of the box of the large incubator are at a minimum at the same ambient temperature. Finally, the optimized small incubator is placed in the large optimized incubator. This structure can then be simulated. In this case, the ambient temperature for the large incubator is equal to the outside ambient temperature. The heat flow of the large incubator is adjusted so that the temperature distribution of the box of the large incubator is close to the target value. The target temperature for the large incubator is the ambient temperature for the small incubator. Based on this, the heat flow of the small incubator is fine-tuned so that the temperature distribution of the box in the small incubator has a further high-precision distribution. This insulation optimization method for improved accuracy is referred to as the SLITA (small optimized incubator placed in large optimized incubator with the same target temperature) method.

The optimized incubator (shown in Figure 9) with vacuum insulation panels was used as a small incubator, and then the small incubator was expanded to a large incubator so that the small incubator could be placed in the large incubator. The heat flow of the large incubator was adjusted at the ambient temperature of $-10^{\circ} \mathrm{C}$ so that the temperature distribution of the box of the large incubator was close to the target value of $25^{\circ} \mathrm{C}$ (shown in Figure 25). Based on this, the heat flow of the small incubator was fine-tuned so that the temperature distribution of the box in the small incubator had a further high-precision distribution of about $25^{\circ} \mathrm{C}$ and the temperature fluctuations of the box of the small incubator were very small. Based on simulation, the target temperature of the box in the small incubator was distributed between $25.000359^{\circ} \mathrm{C}$ and $25.000345^{\circ} \mathrm{C}$ (shown in Figure 26), and the temperature fluctuations of the box of the small incubator were $0.000014^{\circ} \mathrm{C}$.

The target temperature fluctuation values of this incubator (shown in Figure 26) were reduced $98.6 \%$ compared to the previous incubators, such as molecular measuring machine and CMM. Thus, the accuracy of the insulation distribution was greatly improved using the SLITA method. 


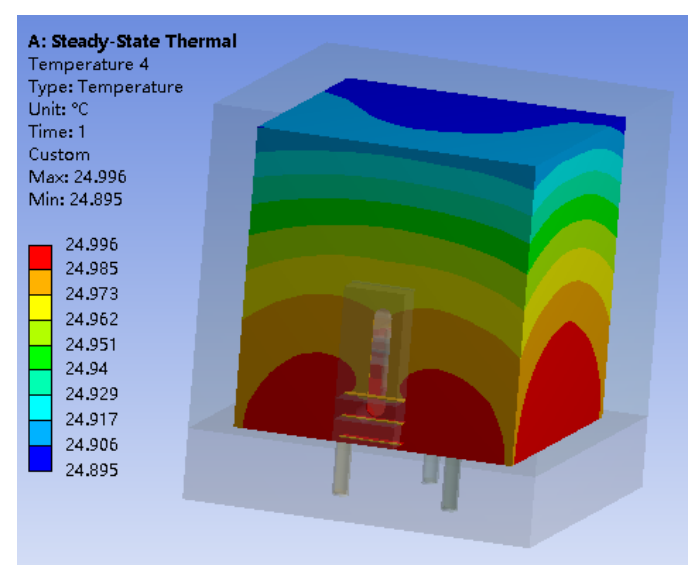

Figure 25. Large incubator temperature distribution.

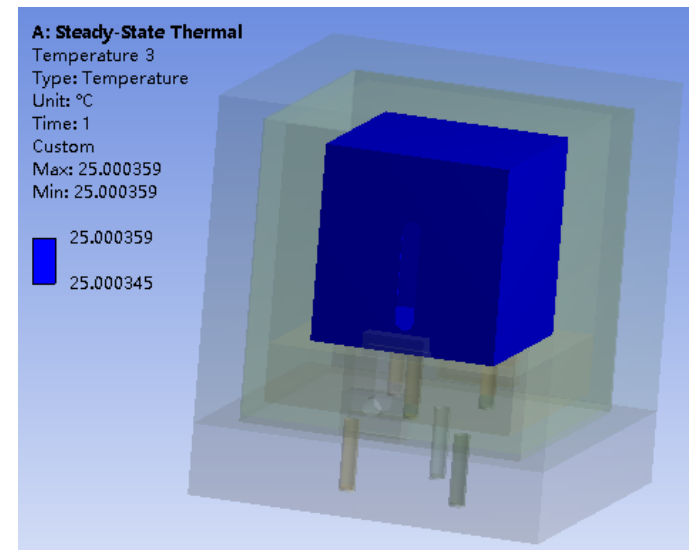

Figure 26. Small incubator temperature distribution.

\section{Conclusions}

In this work, the principle and function of each main structural component of combined incubator were introduced in detail. A small-scale incubator was then designed for FLC and LCVR polarization optics experiments. The incubator has an adjustable light window, anti-stray light, adjustable instrument accuracy, and heat-preservation function. At the same time, ANSYS was used to simulate the temperature distribution of the incubator at $-10^{\circ} \mathrm{C}$. The temperature fluctuations of the box reached $\pm 0.1^{\circ} \mathrm{C}$ through several optimizations. The relationship between the ambient temperature and the target temperature as well as the temperature fluctuations of the box was analyzed. The relationship showed a good linearity. From Formulas (5) to (8), the formula for the relationship was obtained as:

$$
c=C|a|
$$

The $C$ changed when the material of the insulation layer and the size of incubator changed. The $C$ did not change for the same incubator. This formula is suitable to natural convection air, and there is no wind. The formula suggested that the lower the difference between ambient temperature and the target temperature was, the smaller the temperature fluctuations of the box were. When we need to control a particular structure at the desired temperature fluctuations, according to this formula and target temperature requirements of this structure, we can control the ambient temperature of this structure to the corresponding temperature value. In this way, the deformation of the structure, material performance, and requirements can be guaranteed. Thus, it can reduce a lot of long-term experiments and the waste of funds. The incubator used for the FLC and LCVR polarization optics experiments was not optimized, but its temperature fluctuations for the box reached $\pm 0.1^{\circ} \mathrm{C}$ easily. 
This was because the target temperature was near the ambient temperature, which was consistent with the formula.

This SLITA method was proposed according to the idea that, when the ambient temperature is close to the target temperature, the temperature fluctuations of the box are smaller. An example was as follows. The optimized incubator with vacuum insulation panels (shown in Figure 9) was placed in a larger optimized incubator with a vacuum insulation panel. The temperature fluctuations of the box of the small incubator were $0.000014^{\circ} \mathrm{C}$ at $-10{ }^{\circ} \mathrm{C}$ with the simulation. The target temperature fluctuation values of this incubator were reduced more than $98.6 \%$ compared to Ultra Precision CMM and were reduced more than $99.72 \%$ compared to Molecular Measuring Machine. At present, the world's highest precision incubators Ultra Precision CMM and Molecular Measuring Machine were known only. It can be seen that the SLITA method will further improve the accuracy of the incubator.

Instruments that only need to be insulated can be placed in the incubator without having to be placed in a large-space air-conditioned room. Precision instruments that require insulation and working accuracy can be placed in this incubator. The incubator can be widely used for optical components, such as FLC and LCVR, to ensure high polarization measurement accuracy. It can also be used for detecting the characteristics of precise mechanical parts, optical parts, instruments, materials, biology, medicine, atom, molecule, and nanotechnology at different temperatures. For nanomachining technology, the machining precision is controlled in the range of $0.1-100 \mathrm{~nm}$. For example, a tube's material was aluminum. Its coefficient of linear expansion is $20 \times 10^{-6} /{ }^{\circ} \mathrm{C}$ and its length is $1 \mathrm{~m}$. The deformation of aluminum tube is required to be controlled at $0.1 \mathrm{~nm}$, so the effect of ambient temperature change on machining accuracy needs to be considered. According to the above conditions, it can be obtained that the ambient temperature fluctuations must be controlled at $5 \times 10^{-6}{ }^{\circ} \mathrm{C}$ to ensure the required machining accuracy of the aluminum tube. At present, there is no such incubator, so it is necessary to create the conditions for the extremely high insulation accuracy of the incubator to achieve nanometer ultra-high precision machining. The SLITA method proposed in this paper to improve the accuracy of the incubator will provide sufficient ambient temperature conditions for the realization of nano ultra-high precision machining. Thus, this incubator ensures that various components are suitable for use in actual production.

Author Contributions: Conceptualization, S.L.; methodology, S.L.; Experiments, Z.S. and S.L.; validation, Z.Q., Z.S. and S.L.; writing-original draft preparation, S.L.; writing-review and editing, Z.Q. and S.L. All authors have read and agreed to the published version of the manuscript.

Funding: This research received no external funding.

Acknowledgments: This work was supported by the National Natural Science Foundation of China (No. 11527804), the National Natural Science Foundation of China (No. 11673084), and the CAS "Light in West China" Program. The authors acknowledge this support.

Conflicts of Interest: The authors declare no conflict of interest.

\section{References}

1. Wu, W.X.; Wu, W.; Wang, S.F. Form-stable and thermally induced flexible composite phase change material for thermal energy storage and thermal management applications. Appl. Energy 2019, 236, 10-21. [CrossRef]

2. Pinto, J.; Paiva, A.; Varum, H.; Costa, A.; Cruz, D.; Pereira, S.; Fernandes, L.; Tavares, P.; Agarwal, J. Corn's cob as a potential ecological thermal insulation material. Energy Build. 2011, 43, 1985-1990. [CrossRef]

3. Zhang, L.; Zhou, K.C.; Wei, Q.P.; Ma, L.; Ye, W.T.; Li, H.C.; Zhou, B.; Yu, Z.M.; Lin, C.T.; Luo, J.T.; et al. Thermal conductivity enhancement of phase change materials with 3D porous diamond foam for thermal energy storage. Appl. Energy 2019, 233-234, 208-219. [CrossRef]

4. Günay, A.A.; Kim, H.; Nagarajan, N.; Lopez, M.; Kantharaj, R.; Alsaati, A., Marconnet, A.; Lenert, A.; Miljkovic, N. Optically Transparent-Thermally Insulating Silica Aerogels for Solar Thermal insulation. ACS Appl. Mater. Interfaces 2018, 10, 12603-12611.

5. Gulfam, R.; Zhang, P.; Meng, Z.N. Advanced thermal systems driven by paraffin-based phase change materials-A review. Appl. Energy 2019, 238, 582-611. [CrossRef] 
6. Kazmi, H.; Suykens, J.; Balint, A.; Driesen, J. Multi-agent reinforcement learning for modeling and control of thermostatically controlled loads. Appl. Energy 2019, 238, 1022-1035. [CrossRef]

7. Cholewa, T.; Siuta-Olcha, A.; Balaras, C.A. Actual energy savings from the use of thermostatic radiator valves in residential buildings-Long term field evaluation. Energy Build. 2017, 151, 487-493. [CrossRef]

8. Daffallah, K.O.; Benghanem, M.; Alamri, S.N.; Joraid, A.A.; Al-Mashraqi, A.A. Experimental evaluation of photovoltaic DC refrigerator under different thermostat settings. Renew. Energy 2017, 113, 1150-1159. [CrossRef]

9. Bomela, W.; Zlotnik, A.; Li, J. A phase model approach for thermostatically controlled load demand response. Appl. Energy 2018, 228, 667-680. [CrossRef]

10. Lan, S.; Yang, Z.J.; Chen, R.; Stobart, R. A dynamic model for thermoelectric generator applied to vehicle waste heat Recovery. Appl. Energy 2018, 210, 327-338. [CrossRef]

11. Chassin, D.P.; Stoustrup, J.; Agathoklis, P.; Djilali, N. A new thermostat for real-time price demand response: Cost, comfort and energy impacts of discrete-time control without deadband. Appl. Energy 2015, 155, 816-825. [CrossRef]

12. Shahzad, S.; Calautit, J.K.; Aquino, A.I.; Nasir, D.S.N.M.; Hughes, B.R. A user-controlled thermal chair for an open plan workplace: CFD and field studies of thermal comfort performance. Appl. Energy 2017, 207, 283-293. [CrossRef]

13. Kramar, J.A.; Jun, J.; Penzes, W.B.; Scheuerman, V.P.; Scire, F.E.; Teague, E.C. Molecular Measuring Machine design and performance. Proc. Am. Soc. Precis. Eng. 2001, 25, 19-22.

14. Kramar, J.A. Nanometre resolution metrology with the Molecular Measuring Machine. Meas. Sci. Technol. 2005, 16, 2121-2128. [CrossRef]

15. Heredero, R.L.; Uribe-Patarroyo, N.; Belenguer, T.; Ramos, G.; Sánchez, A.; Reina, M.; Pillet, V.M.; Álvarez-Herrero, A. Liquid-crystal variable retarders for aerospace polarimetry applications. Appl. Opt. 2007, 46, 689-698. [CrossRef]

16. Kargar, F.; Barani, Z.; Lewis, J.S.; Debnath, B.; Salgado, R.A.; Aytan, E.; Lake, R.; Balandin, A.A. Thermal Percolation Threshold and Thermal Properties of Composites with High Loading of Graphene and Boron Nitride Fillers. ACS Appl. Mater. Interfaces 2018, 10, 37555-37565. [CrossRef]

17. Shi, H.; Ma, C.; Yang, J.; Zhao, L.; Mei, X.S.; Gong, G.F. Investigation into effect of thermal expansion on thermally induced error of ball screw feed drive system of precision machine tools. Int. J. Mach. Tools Manuf. 2015, 97, 60-71. [CrossRef]

18. Moraveji, A.; Toghraie, D. Computational fluid dynamics simulation of heat transfer and fluid flow characteristics in a vortex tube by considering the various parameters. Int. J. Heat Mass Transf. 2017, 113, 432-443. [CrossRef]

19. Toghraie, D. Numerical thermal analysis of water's boiling heat transfer based on a turbulent jet impingement on heated surface. Physica E 2016, 84, 454-465. [CrossRef]

20. Hosseinnezhad, R.; Akbari, O.A.; Afrouzi, H.H.; Biglarian, M.; Koveiti, A.; Toghraie, D. Numerical study of turbulent nanofluid heat transfer in a tubular heat exchanger with twin twisted-tape inserts. J. Therm. Anal. Calorim. 2018, 132, 741-759. [CrossRef]

21. Pourdel, H.; Afrouzi, H.H.; Akbari, O.A.; Miansari, M.; Toghraie, D.; Marzban, A.; Koveiti, A. Numerical investigation of turbulent flow and heat transfer in flat tube. J. Therm. Anal. Calorim. 2019, 135, 3471-3483. [CrossRef]

22. Yang, J.Y.; Li, J.P.; Feng, R. Heat loss analysis and optimization of household solar heating system. Heat Transf. Res. 2019, 50, 659-670. [CrossRef]

23. US Patent No5061541. Available online: https://patents.google.com/patent/US5061541A/en (accessed on 26 August 2020). [CrossRef]

24. Munoz, F.D.; Anderson, B.; Cejudo-López, J.M.; Carrillo-Andrés, A. Uncertainty in the thermal conductivity of insulation materials. Energy Build. 2010, 42, 2159-2168.

25. Jeon, C.K.; Lee, J.S.; Chung, H.; Kim, J.H.; Park, J.P. A Study on Insulation Characteristics of Glass Wool and Mineral Wool Coated with a Polysiloxane Agent. Adv. Mater. Sci. Eng. 2017, 2017, 3938965. [CrossRef]

26. Liu,S.J.; Zhu, K.M.; Cui, S.; Shen, X.D.; Tan, G. A novel building material with low thermal conductivity: Rapid synthesis of foam concrete reinforced silica aerogel and energy performance simulation. Energy Build. 2018, 177, 385-393. [CrossRef] 
27. Qu, Z.Q.; Deng, L.H.; Dun, G.T.; Chang, L.; Zhang, X.Y.; Cheng, X.M.; Allington-Smith, J.; Murray, G.; $\mathrm{Qu}$, Z.N.; Xue, Z.K.; et al. On the Combination of Imaging-polarimetry with Spectropolarimetry of Solar Upper Atmospheres during Solar Eclipses. Astrophys. J. 2013, 774, 71. [CrossRef]

28. Gisler, D.; Feller, A.; Gandorfer, A. Achromatic liquid crystal polarisation modulater. In Polarimetry in Astronomy; International Society for Optics and Photonics: Waikoloa, HI, USA, 2003; pp. 45-54. [CrossRef]

29. Yang, S.M.; Zhang, Z.Z. An experimental study of natural convection heat transfer from a horizontal cylinder in high Rayleigh number laminar and turbulent regions. In Proceedings of the 10th International Heat Transfer Conference, Brighton, UK, January 1994; pp. 185-189.

30. ANSYS CFX-Solver Theory Guide. (n.d.). Available online: http://www.ansys.com (accessed on 7 September 2020).

31. Bornkessel, T.; Schäfer, M.; Kühn, J.; Emde, P. Thermal Analysis of the Me chanical Structure of the Solar Telescope GREGOR. Art Bull. 2004, 45, 239-251.

32. Volkmer, R.; Lühe,O.V.D.; Soltau, D.; Emde, P.; Krödel, M.; Pailer, N.; Wiehr, E. Optical and thermal design of the main optic of the solar telescope GREGOR. Proc. SPIE 2003, 5179, $270-281$.

33. Qu, Z.Q.; Chang, L.; Cheng, X.M.; Allington-Smith, J.; Murray, G.; Dun, G.T.; Deng, L.H. Prototype FASOT. Astron. Soc. Pac. 2014, 489, 263-271.

Publisher's Note: MDPI stays neutral with regard to jurisdictional claims in published maps and institutional affiliations.

(C) 2020 by the authors. Licensee MDPI, Basel, Switzerland. This article is an open access article distributed under the terms and conditions of the Creative Commons Attribution (CC BY) license (http://creativecommons.org/licenses/by/4.0/). 